\title{
El yaraví de Melgar Signo de emancipación de la literatura peruana
}

\author{
InÉs LiLIANA Ramírez DuRAND
}

\author{
¡Oh Soledad amable! \\ En ti vive el sosiego \\ Que el hombre en otra parte busca en vano \\ Su deseo insaciable \\ Aviva el mundo; y luego \\ Niega lo que ofrecía: ¡infiel tirano! \\ Solo aquí el pecho humano \\ Se engaña felizmente, \\ Le asusta del retiro la apariencia, \\ Mas viene a la experiencia \\ Y encuentra paz y gusto solamente. \\ ¡Qué tranquilo se goza \\ Cuando en paz dulce el corazón se reposa!
}

(Melgar, 1878, p. 104)

El poeta arequipeño Mariano Melgar estudió en el Seminario de San Jerónimo y allí aprendió artes, filosofía, matemáticas, latín, griego, entre otras disciplinas que, sumadas al contexto cultural y situacional de su natal Arequipa, le permitieron conocerse a sí mismo y forjar una identidad que lo impulsó a marcar distancia de la línea conservadora paterna. Entonces, muy lejos de preferir el servicio eclesiástico como lo dispuso su padre, le atrajeron más las artes del conocimiento y el interés por comprender su entorno inmediato: el amor y su pueblo.

De joven, Melgar ocupó en Arequipa la cátedra interina de Latinidad y Retórica bajo el nombramiento del obispo Luis Gonzaga de la Encina y Perla, quien le confiere las 
Órdenes Menores, y no del obispo Chávez de la Rosa como se consideraba convencionalmente, según Miró Quesada (1978). Con el transcurrir de su cátedra, asume la tutela del curso de Filosofía en enero de 1811, fecha en la que es nombrado bibliotecario del Seminario de San Jerónimo.

Estuardo Núñez, por su parte, plantea la hipótesis de que Mariano Melgar recibiera influencia de la poesía italiana y neoclásica en su estancia en Lima en la Universidad de San Marcos (Núñez, 1968). Para Estuardo Núñez, la producción de Melgar es universal y no una poesía simple, como lo afirmaba Riva Agüero. También recalca que, a partir de su estadía en Lima, se plasma en su obra la influencia de fabulistas europeos como en su fábula El ruiseñor y el calesero, publicada en el diario limeño ya extinto El investigador el 2 de octubre de 1813.

De acuerdo con Gregorio Paz Soldán en Los anales universitarios del Perú, Melgar escribió un compendio en latín de la historia de la Filosofía; por otro lado, se ha hallado evidencias de su gusto por la música, reflejado en la composición (traducción) de un miserere (salmo) hallado por Arndt Von Gavel, composición en la que figuran los créditos de letra y música de Mariano Melgar. Ten mi Dios, mi bien, mi amor,/Misericordia de mí [...] (Von Gavel, 1973). A partir de su dominio del latín, y como ejercicios de retórica, traduce textos valiosos de la literatura latina; por ejemplo, el libro IV de las Geórgicas de Virgilio (versos 450-530), que trata sobre la segunda pérdida de Eurídice. Logró la traducción del latín más cercana al castellano, de los Remedia amoris de Publio Ovidio Nasón, por su fidelidad y riqueza lírica. Miró Quesada señala que la traducción melgariana de Ovidio se ubica por encima de la versión antigua de Luis Carrillo de Sotomayor, versión de los Remedia amoris de 1613 y de Diego Suárez de Figueroa que tituló a la obra en castellano como Remedios de amor impuro (1733).

Podríamos decir, además, que su entorno académico lo rescató de posibles carencias económicas, debido a la limitada dote con la que contaría; pero, progresivamente, sus vínculos sociales le permitieron conocer y conservar el sentimiento andino a través del arte. Así, internalizó, posteriormente, elementos de la lírica andina para fusionarlos con su destreza poética occidental, pues sintió dolor y aprendió el sentir de los dolientes. Ello lo podemos notar en su Oda a la Libertad, con motivo del Ayuntamiento Constitucional de Arequipa:

"Siempre seré oprimido",

Pensó el indio infeliz dentro del pecho,

Bajo su pobre techo, 
De su triste familia circuido,
Lloró sobre sus hijos su quebranto,
Y la esposa bebió su amargo llanto.

(Melgar, 1878, p. 100)

Melgar comprendió que no existe, en la trascendencia, la posibilidad de ser fugaz. La educación y la creación son trascendencia, es lo que nos diferencia y nos ayuda a tomar decisiones y, con ella, en el plano formativo, se pueden forjar valores; pero, definitivamente, no se puede transmitir nada si no se toma la decisión de trascender. Para Melgar, la inteligencia espiritual no tenía por qué estar unida al servicio de la religión y se lo hizo saber a su padre al abandonar el rumbo clerical para cumplir otro objetivo, en principio académico, pero luego en la lucha independentista, que lo llevó a ser reconocido como un poeta patriota. Así lo indica, por ejemplo, el general Guillermo Miller, militar británico que participó en la Expedición Libertadora del Perú y recibió información valiosa sobre el papel de Melgar en el periodo emancipador. Miller reconoce el talento literario y la valía personal del poeta arequipeño:

Entre los patriotas sentenciados a muerte y ejecutados, lo fue Melgar [...] natural de Arequipa, que era el Moore del Perú, el cual compuso algunas canciones o yaravíes, del que pudiera engreírse el autor del Lallah Rookh. La muerte de Melgar produjo un sentimiento general, y su memoria se conserva aún con respeto. (Miller, 1910, p. 74)

Como vemos, aunque son algo imprecisos los datos sobre su actitud cuando iba a ser ejecutado (12 de marzo de 1815), la documentación existente ratifica su rol en pro de la sublevación de los indios en las provincias del Cusco, Apurímac y Arequipa, bajo el liderazgo del brigadier Mateo García Pumacahua (cacique de Chinchero) y José Angulo, quienes con un gran grupo de jóvenes arequipeños y de otras provincias que se iban sumando a la causa, buscaban la independencia peruana del poder español. Entonces, a la edad temprana de veinticuatro años Melgar deja un legado de obra y acción. Su ejecución por orden del general Ramírez, ya que había cumplido el rol de auditor general de guerra del ejército republicano, es narrada por Miller de la siguiente manera:

El cura nombrado para acompañarle al suplicio principió a exhortarle en el bronco estilo y bárbaras maneras con que acostumbran comúnmente a hacerlo, pero Melgar le contestó en alta voz: "Padre, no es el momento de hablar de política ni de cosas de este mundo, vine preparado a este sitio para morir; pero usted me ha distraído, Que me den un cigarro". En efecto, se lo trajeron, y después de haber fumado cerca de la mitad de él, y adquirido nuevamente su tranquilidad, dijo serenamente que estaba pronto para morir, y murió con una firmeza varonil y digna de su persona. (Miller, 1910, p. 74) 
De acuerdo con Aurelio Miró Quezada (1978), fue en el mes de noviembre de 1814 que Melgar se incorporó a las filas de la columna patriótica que se formó en Chuquibamba y se dirigió con ella a Arequipa. Así la exaltación del nuevo espíritu inspiró a Melgar la Marcha patriótica, que debió de escribir por esos días y que contrasta con el llamado a la confraternidad de sus odas anteriores (Miró Quesada, 1978, p. 139):

Viva, viva eternamente,

el Patriotismo peruano,

Viva el suelo Americano,

Viva su libertador.

(Melgar, 1997, p. 67)

En las distintas composiciones literarias de Melgar podemos encontrar evidencias del distanciamiento parcial de la poesía occidental y su apego progresivo a formas y temáticas típicas peruanas. Así, Melgar, en sus yaravíes, hace uso de los elementos interculturales para reflejar un nuevo espíritu, el simbolismo y la cosmovisión de la cultura andina, que dan como resultado un ejemplo de legado literario que sirve para expresar penas de amor y el arraigo o pertenencia a una comunidad mestiza y diversa como ya lo era la sociedad peruana en ese entonces.

El yaraví debe su existencia a los cantos andinos prehispánicos llamados harawi, que perduran a través de los siglos gracias a la perseverancia del pueblo. Es, pues, un arte verbal de antigua data. Aunque la falta de escritura no ha permitido fijar los límites exactos de su evolución, se logró ampliar el concepto del harawi. Raúl Porras Barrenechea confirma que el concepto es amplio y múltiple en el siglo XVI, pero es restringido, por obvias razones de ocupación española (Porras, 1946).

Durante el periodo colonial, Fray Gonzales Holguín definió al harawi como "Cantares de hechos de otros o memoria de los amados ausentes y de amor y afición y agora se ha recibido por cantares devotos y espirituales" (Holguín, 1608). Asimismo, en Los comentarios reales, el Inca Garcilaso define a los harawis como cantos empleados en los ritos andinos prehispánicos (Vega, 1609); mientras que Phelipe Guamán Poma de Ayala los refiere en su majestuosa Nueva corónica y buen gobierno como cantos araui en quechua y aimara que eran entonados por la población indígena en distintas celebraciones o situaciones cotidianas (Poma de Ayala, 1615). 
Washington Delgado define el haraui como una melancólica canción de amor, plagada de nostalgia, que se entona en el sur del Perú y que dio origen al yaraví moderno, cultivado por Melgar a inicios de la Independencia, una etapa en la que los temas indígenas fueron abordados, aunque superficialmente. Los temas abordados en estos cantos, de acuerdo con Delgado, son desamor y ausencia de la persona amada, a diferencia de los huaynos, que expresan el humor, la ternura y la sabiduría de los pueblos quechuas. Asimismo, es menester señalar, de acuerdo con Delgado, que la poesía popular quechua destaca por su flexibilidad y hondura (Delgado, 1980):

$$
\begin{aligned}
& \text { Blanca nube la más leve, } \\
& \text { clara fuente de agua pura, } \\
& \text { tú serás mi dulce engaño, } \\
& \text { yo seré tu oscura sombra. }
\end{aligned}
$$$$
\text { (Lara, 1979, p. 172) }
$$

Ahora bien, la literatura prehispánica presenta ciertas características relevantes. Entre ellas, podemos destacar, la oralidad, el carácter agrarista (el respeto idolatrado a la tierra), el pensamiento clasista y la atención en el cosmos. Por su parte, Víctor Vich y Virginia Zavala (2004) señalan que la oralidad es un rasgo inherente a las lenguas en su origen; por ende, las condiciones de una sociedad productora de patrimonio cultural son las mismas desde el punto de vista lingüístico. Al hablar de oralidad, también debemos mencionar el concepto de literacidad, que es el conjunto de prácticas sociales de análisis y transformación de información situadas en la lectura y la escritura. Aunque la división tajante entre oralidad y literacidad es ideológica, se debe tener en cuenta que esta última no es sinónimo de literacidad educativa; por eso, hay que considerar los factores culturales (el género, la forma de percibir la comunicación cara a cara) que inciden en los múltiples usos de lo oral y lo escrito.

Así pues, la literacidad está centrada en la comprensión básica del lenguaje y en los roles dinámicos del lector y el escritor en un contexto determinado, condicionado por tradiciones y comportamientos colectivos. Sin embargo, es la oralidad la que nos permite fijar las tradiciones y reconstruir las raíces simbólicas de las comunidades. En ese sentido, las distintas sociedades constituyeron su representación colectiva y las esencias nacionales, capaces de resistir los cambios del tiempo y de integraciones vinculadas con otros pueblos. Es la oralidad la que nos permite conocer las raíces culturales de un pueblo, pueblo que, con el transcurrir del tiempo, se convierte en sociedad letrada. 
Si tenemos en cuenta que las naciones occidentales, al igual que la andina, se desarrollaron inicialmente en torno de las culturas ágrafas, las narrativas nacionales estuvieron al servicio de la formación de una cultura homogénea (la identidad esencial y diferenciada de otras: el Volksgeist ${ }^{1}$ ). Sin embargo, lamentablemente, incluso hasta inicios de la República, la construcción del concepto de nación se siguió abordando, por muchos, desde su vínculo con lo letrado. Desde la perspectiva de un grupo ilustrado de personas, la cultura occidental se consideró como la única válida. Es decir, se buscaba desacreditar o invalidar la cultura andina producida por la población indígena o mestiza, con el pretexto de la búsqueda del 'auténtico' progreso y la civilización. Así, para América, la identidad cultural surgía de la idea de asemejarse a Occidente, lo cual incluía la erudición y la homogeneización de la escritura (castellana) que proponía el grupo de hombres ilustrados que veían lo indígena como lo no civilizado y desprovisto de riqueza cultural.

Si bien es cierto que la oralidad nos lleva a hablar de anonimato, característica que no permite fijar el punto exacto de la fuente original, existe la enorme ventaja de atribuir, con esto, la autoría a la colectividad popular, proveniente del 'rumor', que va guardando en su memoria colectiva datos ficcionales que transmite de generación en generación. Vemos pues, que el anonimato no es una desventaja, sino que representa la oportunidad de seguir construyendo un canon literario nutrido de la diversidad cultural.

La tradición literaria andina centra su atención en el cosmos, porque la colectividad consideraba al universo como el facilitador de la vida del hombre y de todo lo que le permite sobrevivir. Para ello, los mitos permiten explicar la dependencia del hombre con respecto de la naturaleza, así como el amor maternal de ésta con el individuo. Cabe señalar que esta naturaleza incluye todo lo observable; es decir, la Tierra y el resto del cosmos, que son considerados seres vivos que protegen o castigan al hombre según su accionar con el entorno natural. Curiosamente, esta misma afinidad cosmogónica se evidencia en la sustentación del origen de los pueblos occidentales y da paso a los pensamientos clasistas y al orden de los grupos, sujetos a los privilegios de los más poderosos. También, la visión agrarista está presente en todo género practicado en las creencias andinas desde antes de la invasión española e, incluso, hasta la fecha; el amor por el campo se refleja en las canciones con diversa temática. Así, el haraui, junto con el haylli, el taki, el ayarachi, la huahuaquilla, el huayno, el huahuaqui, entre otros, constituyen la expresión más pura y sublime que se relaciona y se funde con la temática de la naturaleza, el amor y la religiosidad cosmogónica.

1 Concepto de nacionalismo romántico que atribuye a cada pueblo rasgos comunes e invariables. 
Es importante aclarar que los cantos andinos han gozado siempre de acompañamiento musical. Durante el periodo prehispánico, los instrumentos fueron hechos de insumos animales o de material artesanal, y son de viento y de percusión. De acuerdo con los estudios de Hachs Hornbostel, las herramientas musicales se agrupan en cuatro tipos: cordófonos, aerófonos, idiófonos y membranófonos (Pérez y Gili, 2013). En este sentido, es necesario recalcar que los instrumentos prehispánicos excluían las cuerdas, que fueron insertadas en los cantos andinos con la influencia española.

Como ya se ha señalado, en la búsqueda de evidencias de una literatura peruana independiente, por mucho tiempo, las manifestaciones andinas pasaron desapercibidas por la crítica colonial o pegada al idealismo occidental. Es con la consolidación del Perú republicano que los estudios culturales se orientan a buscar símbolos que evidencien la identidad social de un pueblo que busca desligarse de la imitación occidental. Al respecto, Washington Delgado señala que de la antigua literatura quechua subsisten algunos temas y motivos que han logrado expresarse con el tiempo en composiciones traducidas o producidas en español. Por la parte occidental, la literatura peruana heredó géneros, estilos y acicalamiento verbal con conceptismo académico. Por ello, es de suponer que para entender sobre la literatura de la Emancipación hace falta considerar aspectos como el verdadero significado de la Independencia para los pueblos vulnerables, las clases sociales y la búsqueda de la idea de nación. Recordemos que la Independencia, en su momento, no significó un cambio positivo para todos los grupos sociales. Las manifestaciones artísticas andinas, por ejemplo, seguían catalogándose como inferiores a las de corte occidental. Además, por la carencia de escritura y la falta de acceso a los tradicionales medios de comunicación masiva de la época, el aporte de la expresión andina no se concretaba oficialmente.

En el ambiente arequipeño, durante el periodo de la Emancipación e inicios de la República, ocurría lo mismo: la presencia de factores sociales que no permitían valorar el aporte de la literatura ancestral prehispánica en su debido momento, ya que los diarios o folletos eran exclusivos para la transmisión del código español. De ello se encuentran los registros en diarios como El Republicano (1825-1855), El Regenerador (1834); El Pensador (1834), El Misti y El Chili (1834).

Según Delgado (1980), con el tiempo se produce la revaloración del sentimiento andino, así como sus formas, a manera de buscar y reflejar la unidad nacional. A esta búsqueda la respuesta es Melgar, ya que es quien recoge el sentimiento andino indígena y lo refleja en los versos castellanos. Para Delgado, semejantes a la connotación del aporte del Inca Garcilaso de la Vega, los yaravíes de Melgar evidencian el inicio del mestizaje cultural y ubican en la literatura escrita en castellano la relación conflictiva entre autoctonismo y occidentalismo, ya que toda literatura anterior había sido regida por la 
tendencia temática y estructural hispanista. Aunque, como señalamos anteriormente, esta inspiración de motivos andinos es limitada a futuro, pues los sucesores románticos Carrasco, Salaverry y Althaus no acrecientan el impulso indigenista de Melgar, ya que lo que se producirá por un periodo prolongado es la influencia neoclásica del siglo XVIII.

De acuerdo con Antonio Cornejo Polar (1989), los yaravíes de Mariano Melgar deben ser reconocidos como obra representativa de la literatura de la Emancipación, la cual forma parte de un proyecto hispano ligado a raíces indígenas, presentes en su lírica; por ejemplo, los rasgos musicales propios, que compaginan la oralidad típica de los grupos indígenas populares, aunque este hecho lo desvincule de una literatura occidentalizada típica del periodo de la Emancipación por el empleo de metáforas andinas y el tono melancólico vinculado con la naturaleza. Esta revaloración de raíces andinas en la lírica melgariana se cumple en la composición de sus yaravíes que, a decir de la definición romántica de Francisco García Calderón en la introducción de las Poesías de Don Mariano Melgar de 1878, es el “iay! que emite el alma” (Melgar, 1878, p. 34). En este sentido, retomemos los límites de la influencia de la lírica andina y el aporte occidental de las composiciones líricas de Melgar y revisemos las aproximaciones conceptuales del término yaraví.

De acuerdo con Aurelio Miró Quesada, el yaraví proviene de la palabra haraui, que es al mismo tiempo manifestación poética quechua, cuyos declamadores recibían el nombre de haravicus o harauec (Miró Quesada, 1978, p. 162). Siguiendo este punto de partida, diremos que los yaravíes son esos cantos mestizos de dulce melodía y un tono melancólico que requieren de acompañamiento musical, la guitarra, y que derivan del haraui andino, cuya diversidad temática no era precisamente melancólica y triste, y que obedece a un producto colectivo acompañado por el marco musical de la quena. El haraui obedecía, a diferencia del yaraví, a la producción colectiva de los miembros de la comunidad andina; mientras que el yaraví surge de una voz individual, por lo que esta libertad le permite al cantor expresar sus sentimientos independientemente de la colectividad a la que pertenece; de allí que el cantor es libre de poder expresar la nostalgia y la pena de amor. Es pues, el yaraví, un producto mestizo que se ha enriquecido con el tiempo y que ha logrado calar y enraizarse en la identidad de los pueblos en los que se practica este canto de estilo trovador.

De acuerdo con Raúl Porras Barrenechea (1946), el origen del yaraví se remonta a la imagen triste y propia de la manifestación artística. Porras sitúa el origen del yaraví de tono enlutado en el siglo XVIII como un producto mestizo. Resulta mestizo porque la pronunciación de palabras agudas en el yaraví no es propia en la cultura andina, más bien es propia de la lengua castellana. Proviene de la voz grave andina haraui, que con el transcurso del tiempo se fue transformando hasta teñirse de melancolía desde el siglo 
XVI hasta aproximadamente 1791, cuando ya se oyen los cantos con el acompañamiento de acordes de guitarra:

Es la modulación que va a prevalecer en la disertación sobre los yaravíes del Mercurio Peruano de 1791 y en la guitarra arequipeña de Melgar. Pedantes profesores de fonética ausentes del alma nueva y criolla del yaraví, aconsejarán más tarde llamarle hjarahui, harawi o Aya aruhui. (Porras, 1946, p. 12)

Es el yaraví una composición que de por sí buscó su legitimación, aunque solo sea considerada en diversas circunstancias históricas.

Desde la época colonial, a través de la Emancipación y gran parte de la República, en Arequipa, como en otras provincias, se fomentaba el encuentro de jóvenes que departían en las campiñas y chicherías y compartían momentos de alegría y de pena, anécdotas que se plasmaban en composiciones particulares: el marco perfecto para componer, cantar y plasmar el cuadro de la interculturalidad andina y criolla.

Para poder entender la base andina del yaraví hace falta compararlo con otro género. Por ejemplo, resulta interesante comparar el yaraví y el huaino, ya que comparten, principalmente, elementos comunes como el diálogo, la naturaleza, las aves (la paloma), la nostalgia y el dolor del yo poético, aunque este último no se evidencia en todos los huainos. El diálogo refleja el grado de cercanía que hay con el alocutario; es decir, hay una búsqueda de conversación en la que el locutor da su testimonio sobre el hecho de separación y manifiesta sus emociones ante este evento. En el huaino Adiós pueblo de Ayacucho, de autor anónimo e interpretado oficialmente por el arpista Estanislao Medina, podemos notar la dirección del mensaje del locutor a un alocutario, que es la misma naturaleza, es decir, la tierra a donde ya no volverá:

Adiós, pueblo de Ayacucho, perlaschallay, donde he padecido tanto, perlaschallay, ciertas malas voluntades, perlaschallay, hacen que yo me retire, perlaschallay.

$$
[\ldots]
$$

Adiós, pueblo de Ayacucho, perlaschallay, ripuqtana qawariway, perlaschallay, por más lejos que me vaya, perlaschallay, no creas que te olvide, perlaschallay.

(Anónimo, 1930) 
Se trata de una canción del sur andino peruano que refleja la despedida doliente de quien no acepta el motivo injusto por el que debe alejarse del lugar que lo alberga, pero que, al mismo tiempo, representa ambigüedad semántica, ya que puede referirse a la mujer amada y a la feminidad del pueblo como madre valiosa. Asimismo, la cercanía entre locutor y alocutario en el Yaraví VII de Melgar es una muestra de ese intento de diálogo de un emisor amante desdichado por la no correspondencia sentimental.

¿Con que al fin, tirano dueño,

Tanto amor, clamores tantos,

Tantas fatigas,

No han conseguido en tu pecho

Más premio que un duro golpe

De tiranía?

Tú me intimas que no te ame

Diciendo que no me quieres,

¡Ay vida mía!

¡Y que una ley tan tirana

Tenga de observar, perdiendo

Mi triste vida!

[...]

Muerto yo, tú llorarás

El error de haber perdido

Un alma fina;

Y aun muerto sabrá vengarse

Este mísero viviente

Que hoy tiranizas.

Á todas horas mi sombra

Llenará de mil horrores

Tu fantasía; 


\section{Y acabará con tus gustos \\ El melancólico espectro \\ De mis cenizas. \\ (Melgar, 1878, pp. 205-206)}

En este yaraví el yo poético individualiza al alocutario, la mujer amada que no corresponde a los sentimientos del poeta, y que es la responsable del dolor del yo poético, quien no encuentra solución ni consuelo ante el abandono del ser amado, que no es una donna angelicata, y que sí es merecedora de reproches. A esta búsqueda de diálogo se suma la identificación de la naturaleza que, la mayoría de veces, se resume en la metáfora de la paloma como imagen de la mujer amada, quien, frecuentemente, no corresponde al locutor. Si bien es cierto, no fue Melgar quien crea la metáfora de la paloma, que líneas más adelante explicaremos de modo lingüístico como símbolo de la femineidad, la recoge y la interioriza profundamente en su sentir y la convierte en una figura de sus composiciones, como fruto de su cercanía al contexto andino. Por otro lado, siglos después, la simbología de la paloma como mujer sigue latente en la memoria colectiva del pueblo peruano; así lo podemos encontrar en el famoso huaino arequipeño Llanto por llanto compuesto por Gilberto Cueva y Héctor Camacho, músicos y compositores del trío Los Errantes de Chuquibamba (Arequipa):

Una paloma sobre una rama abre su pico para cantar La rama tiembla como quien dice, ¡Ay, tú, no sabes lo que es amar! La rama tiembla como quien dice, ¡Ay, tú, no sabes lo que es amar! Yo te he querido, yo te amado, tu no has sabido corresponder

Gota por gota, llanto por llanto, mis ilusiones se acabaron

$$
[\ldots]
$$

Cuando me vaya solo te pido que no me borres de tu memoria

Por algo he sido siquiera un día, tu fiel amante, palomita Por algo he sido siquiera un día, tu fiel amante, palomita Ay llorando, llorando nomás estas Ay no llores no llores porque me voy.

(Camacho, 2000) 
Generalmente, ante la pérdida progresiva del quechua, la memoria colectiva andina ha logrado conservar muchas simbologías y formas lingüísticas que se adaptaron en el registro castellano como urpi (paloma) y los diminutivos. Un ejemplo de la valoración de estos rasgos lo encontramos en el yaraví representativo de Mariano Melgar:

Vuelve, que ya no puedo

Vivir sin tus cariños:

Vuelve mi palomita,

Vuelve a tu dulce nido

Mira que hay cazadores

Que con afán maligno

Te pondrán en sus redes

Mortales atractivos;

Y cuando te hagan preso

Te darán cruel martirio:

No sea que te cacen,

Huye tanto peligro.

Vuelve mi palomita,

Vuelve a tu dulce nido

$$
\text { [...] }
$$

No vueles más, no sigas

Tus desviados giros;

Tus alitas doradas

Vuelve a mí, que ya espiro

Vuelve que ya no puedo

Vivir sin tus cariños,

Vuelve mi palomita,

Vuelve a tu dulce nido

(Melgar, 1878, pp. 196-198)

El yo poético implora por el retorno del ser amado que lo ha abandonado, pero elige la expresión mi palomita, que evidencia la asimilación de la herencia lingüística 
quechua, castellanizada: Urpichay, mi palomita en castellano. Al sustantivo urpi se suman los sufijos -cha- (pequeña) e -y (mía). Melgar pudo, por sus conocimientos eruditos de literatura latina clásica, emplear vocablos bucólicos como los de sus sonetos o cartas, que tenían como alocutarios a Melisa o Silvia, pero plasma, en su yaraví, la imagen típica andina de paloma para referirse al ser amado. Demuestra, entonces, la identificación con la diversidad cultural que ha reconocido como suya a través de estos dos elementos: el símbolo de paloma (mujer) y el sustantivo diminutivo palomita, empleado por una sociedad mestiza y andina a la vez, que ha conservado hasta la actualidad el uso de diminutivos en el castellano peruano. Asimismo, las estrofas conservan la intencionalidad comunicativa y la carga semántica de dolor y reclamo, pero un reclamo cariñoso que busca el diálogo con el otro.

La composición polirrítmica de sus versos muestra una búsqueda de libertad y sencillez, a diferencia de los sonetos o traducciones que reflejan mayor complejidad métrica y de rima. Sin embargo, los yaravíes cumplen la finalidad de reflejar un profundo sentir en estrofas que muestran el mestizaje perfecto del arte peruano.

Para José Carlos Mariátegui (1979), Melgar es el primer poeta que expresa el sentimiento indígena en la literatura peruana a través de su obra lírica, calificada por la crítica limeña como popular por la cercanía con temas sentimentales y versificación breve, pero revalora su carácter romántico que, a diferencia del resto de escritores, no es un romántico por imitación, sino por naturaleza y, muy por el contrario de la concepción tradicional y elitista que se tiene de Melgar, debe de ser valorado como el primer poeta peruano de formación culta que fusiona la influencia lírica del mundo andino con un código y estilo particular heredado de lo estándar aceptado por la cultura dominante del poblador criollo.

Finalmente, con el yaraví de Melgar, como estructura estrófica, y con el marcado romanticismo que reflejan sus letras, cargadas de intensidad y pasión, se identifica el inicio de la poesía peruana como tal, porque refleja una lírica intercultural que no solo demuestra identidad formada por la heterogeneidad, sino que marca un hito en la historia una literatura peruana. El poeta arequipeño es la muestra del espíritu de una sociedad que busca crear su propia historia a partir de una patria independiente que envuelve al mundo andino, criollo y mestizo. Melgar dejó un legado significativo que nos permite valorar la cultura peruana sin segmentarla para sostener vínculos que fortalezcan la idea de nación. 


\section{BIBLIOGRAFÍA}

Anónimo (1930). Adiós, pueblo de Ayacucho [Grabado por E. Medina]. [disco]. Ayacucho, Perú. https://soundcloud.com/dario-mejia/adi-s-pueblo-de-ayacucho

Camacho, H. (2000). Llanto por llanto [Grabado por G. Cueva]. Arequipa, Arequipa, Perú: Iempsa. https://www.discogs.com/es/Los-Errantes-Los-Errantes/release/11287895

Cohen, A. (1982). Belonging: Identity and Social Organisation in British Rural Cultures. Manchester University Press.

Cornejo, A. (1989). La formación de la tradición literaria en el Perú. Centro de Estudios y Publicaciones CEP.

Cornejo, A. (1989). Sobre la literatura de la emancipación en el Perú. 90-93. https://pdfs.semanticscholar.org/ce30/da343ee7b6d0a24c96996362fc94fda69f48.pdf

Cuadros, T. C. (2003). Literatura arequipeña. Editorial UNSA.

Delgado, L. H. (1972). Pablo de Olavide y Mariano Melgar. El Monstruo y el Héroe. Latino América Editores.

Delgado, R. E. (1967). Mariano Melgar, romántica personificación de un precursor de la Independencia del Perú. : Universidad Nacional de San Agustín, Fondo Editorial.

Delgado, W. (1980). Historia de la literatura republicana: Nuevo carácter de la literatura en el Perú. Ediciones Rikchay.

Farfán, J. (1952). Colección de textos quechuas del Perú. En Colección de textos quechuas del Perú. Politécnico Nacional José Pardo.

García-Bedoya, C. (1990). Para una periodización de la literatura peruana. Latinoamericana Editores.

Guamán Poma de Ayala, P. (1615). Nueva corónica y buen gobierno. Biblioteca Ayacucho.

Higgins, J. (2006). Historia de la literatura peruana. Editorial Universitaria.

Holguín, D. G. (1608). Vocabulario de la lengua general de todo el Perú llamada Quichua, o del Inca. Imprenta de Francisco del Canto.

Lara, J. (1979). La poesía quechua. FCE.

Mariátegui, J. C. (1979). "El proceso de la literatura". En J. C. Mariátegui, Siete ensayos de la interpretación de la realidad peruana (pág. 221). Biblioteca Ayacucho. Recuperado de: http:// biblioteca.clacso.edu.ar/clacso/se/20191120045233/7_ensayos_de_interpretacion_de_ la_realidad_peruana.pdf

Melgar, M. (2 de 11 de 1813). El ruiseñor y el calesero. El Investigador (XXXII), pp. 125-126.

Melgar, M. (1878). Poesías de Don Mariano Melgar. Edición de Manuel Moscoso Melgar.

Melgar, M. (1997). Mariano Melgar. Poesía completa. UNSALIBROS. EL PUEBLO . 
Melgar, M. (1997). Ya llegó el dulce momento. UNSALIBROS EL PUEBLO.

Miller, J. (1910). Memorias del general Guillermo Miller al servicio de la República del Perú (Trad. G. Torrijos). Librería General de Victoriano Suárez. https://bvpb.mcu.es/es/catalogo_ imagenes/grupo.do?path=140084

Miro Quesada, A. (1978). Historia y leyenda de Mariano Melgar. Ediciones Cultura Hispánica del Centro Iberoamericano de Cooperación.

Nason, O. (1993). Arte de olvidar o Remedio de amor. Traducción de Mariano Melgar. Saywa.

Núñez, E. (1968). “Mariano Melgar y sus posibles fuentes itálicas”. En E. Núñez, Las letras de Italia en el Perú, pp. 41-57. Universidad Nacional Mayor de San Marcos, Fondo Editorial.

Orbe, R. C. (2012). La República inconclusa. Universidad Inca Garcilaso de la Vega, Fondo Editorial.

Pérez, J., y Gili, F. (2013). “Clasificación Sachs-Hornbostel de instrumentos musicales: una revisión y aplicación desde la perspectiva americana". Revista musical Chilena, 67 (219), 42-80. https://dx.doi.org/10.4067/S0716-27902013000100003

Porras Barrenechea, R. (28 de julio de 1946). Apuntes para una biografía del yaraví. El Comercio p. 12.

Rada, P. (1950). Mariano Melgar y apuntes para la historia de Arequipa. Casa Nacional de Moneda.

Riva-Agüero, I. (1971). Estudios de la historia peruana: La emancipación y la república. Pontificia Universidad Católica del Perú, Fondo Editorial.

Riva-Agüero, J. d. (1962). La imitación en la literatura peruana.- literatura colonial.-Melgar. -Olmedo.- Larriva.- Valdes.- Prosistas de los primeros añosde la independencia.- Don José María de Pando- Influencia de mora. En J. d. Riva-Agüero, Carácter de la literatura del Perú independiente, pp. 73-131. Pontificia Universidad Católica del Perú.

Sánchez, L. A. (1998). La literatura peruana. Tesis universitaria. Lima: Instituto Luis Alberto Sánchez.

Turpo, F., Zúñiga, J., Hidalgo, J., Ydme, P., Becerra, A., y Monzón, L. (2015). Mariano Melgar. Libro de homenaje póstumo a Mariano Lorenzo Melgar Valdivieso. Colegio de Abogados de Arequipa.

Varallanos, J. (1989). El harahui y el yaraví. Dos canciones populares peruanas. Argos.

Vega, I. G. (1609). Comentarios reales (Vol. II). Pedro Crasbeeck.

Vich, V., y Zavala, V. (2004). Oralidad y poder: herramientas metodológicas. Grupo editorial Norma.

Von Gavel, A. (21 de octubre de 1973). El 'miserere' de Melgar. Suplemento El Dominical, El Comercio. 